\title{
Flood modelling: parameterisation and inflow uncertainty
}

Micah M. Mukolwe MSc

PhD Participant, Unesco-IHE Institute for Water Education, Delft, the Netherlands

Giuliano Di Baldassarre PhD

Senior Lecturer in Hydroinformatics Systems, Unesco-IHE Institute for Water Education, Delft, the Netherlands
Micha Werner PhD

Associate Professor of Hydraulic Engineering, Unesco-IHE Institute for Water Education, Delft, the Netherlands

Dimitri P. Solomatine PhD

Professor of Hydroinformatics, Unesco-IHE Institute for Water Education, Delft, the Netherlands; Water Resources Section, Delft University of Technology, Delft, the Netherlands

This paper presents an analysis of uncertainty in hydraulic modelling of floods, focusing on the inaccuracy caused by inflow errors and parameter uncertainty. In particular, the study develops a method to propagate the uncertainty induced by, firstly, application of a stage-discharge rating curve and, secondly, parameterisation of a onedimensional hydraulic model by way of the power function and the conditioning of Manning's roughness coefficients. The proposed methodology was applied to a $98 \mathrm{~km}$ reach of the River Po, Italy. Model performance was evaluated using two independent sets of observed water levels in the river reach within a generalised likelihood uncertainty estimation framework. The inflow uncertainty was found to have a greater contribution to the overall uncertainty of the 1D model than the roughness parameters. Independent parameter conditioning and validation, as well as the uncertainty analysis, showed satisfactory model performance. When conditioned on one flood event, the model adequately simulated flood levels and high water marks for another (independent) event, as the observations were within $90 \%$ confidence interval of the simulation ensemble.

\author{
Notation \\ A area \\ $H \quad$ water level \\ $H_{0} \quad$ water level corresponding to zero discharge \\ $h \quad$ water depth \\ $n \quad$ Manning's roughness coefficient \\ $Q \quad$ discharge \\ $R \quad$ hydraulic radius \\ $S_{0} \quad$ user-specified friction slope \\ $\Delta t \quad$ computation time step \\ $u \quad$ flood wave velocity \\ $\Delta x \quad$ cross-section spacing
}

\section{Introduction}

Flood disasters pose an ever-present danger to people and the environment, as witnessed in the recent flood occurrences in Bangkok in 2011 and Jakarta in 2013. The response to flood hazard is generally based on the construction and reinforcement of structural defences, and the implementation of non-structural measures such as land use, urban planning and the provision of flood forecasting and warning (Kidson and Richards, 2005). To ensure safe habitation of floodplains and plan appropriate risk reduction measures, knowledge of the spatial distribution of the flood hazard is necessary (Loucks et al., 2005).

The achievement of 'as accurate as possible' characteristics of the flood hazard is a research challenge that is widely addressed. Flood mitigation methodologies to deal with prior flood warning, quantification of envisaged disasters, uncertainty in flood risk management tools and coping mechanisms are continuously being researched (e.g. McCarthy et al., 2007; Montanari, 2007; Pappenberger and Beven, 2006). These initiatives are bolstered by the availability of ever-increasing computer power and new models developed to analyse hydro-meteorological inputs and generate flood warnings and estimates of flood extent and other specific hazard characteristics; new information sources such as spatial data derived from satellite imagery are also increasingly becoming available (Bates, 2012; Di Baldassarre et al., 2009a, 2009b; Schumann et al., 2009). These improvements in flood risk management tools and methodologies result in a reduction of flood risk.

One-dimensional (1D) hydraulic modelling is commonly used in computationally intensive applications such as Monte Carlo analysis and probabilistic mapping of outputs (e.g. Di Baldassarre et al., 2009a; Pappenberger et al., 2006; Quiroga et al., 2013). Reduced-complexity two-dimensional (2D) hydraulic model codes are gaining popularity, given their computational efficiency when compared with fully physically based 2D model codes, and have even been applied in large-scale flood inundation case studies (e.g. Bates et al., 2010; Dottori and Todini, 2011; Hunter et al., 2005a, 2005b; Neal et al., 2012). The selection of hydraulic models is typically based on a trade-off among the different factors of physical realism, computational efficiency, consistency with the quantity and quality of input and observation data, and objectives of the specific study. 
The primary data requirements of 1D hydraulic models are the system boundary conditions (upstream and downstream) and terrain characteristics such as the topography and effective roughness values (Pappenberger et al., 2005, 2006). Discharge hydrographs (often derived from measured water levels using rating curves) are typically used as the upstream boundary condition. Water level measurement accuracy is reported to be relatively high, with commonly used measurement instruments having an accuracy ranging from 2 to $15 \mathrm{~mm}$ (Boiten, 2008). However, indirectly observed river discharges are affected by significant uncertainty (Clarke, 1999; Di Baldassarre and Montanari, 2009).

The rating curve is an empirical relation between the measured water level and the discharge in an open channel. Parameterisation of the rating curve is dependent on the accuracy of measurement of the discharge and water levels. However, these measurements are affected by uncertainty, broadly classified either as random natural occurring errors or due to lack of knowledge of the behaviour of the natural system (Braca, 2008). Some of the main sources of rating curve error Neal et al. show an example of a practical case in which the rating curve for a gauging station had to be revised using a hydraulic model due to significant inconsistency in the measured rating curve and the actual flood event. Sources of rating curve error include those induced by

- geometrical changes in the cross-section configuration due to sediment transport

vegetation growth and depletion and the resulting effect on bed roughness

- the time interval with which rating curves are updated

- the presence of unsteady flow and backwater effects (Boiten, 2008; Di Baldassarre and Montanari, 2009; Pappenberger et al., 2006)

A rating curve is a cross-section-specific relationship between the water stage and the corresponding flow discharge and is often represented by a piecewise power law or polynomial functions to fit observed water levels and discharge data (Braca, 2008; Fenton, 2001). In this study, rating curves were derived by fitting a power-law function with two parameters (Di Baldassarre and Montanari, 2009; Herschy, 1999) to contemporaneous observations of river flow and water stage. The power function is widely used for stage-discharge rating curves because of its parsimony and hydraulic justifications (Fenton, 2001; Petersen-Øverleir, 2005). Functions that are more complex have been developed to better capture transitions to overbank flow. For instance, Reitan and Petersen-Øverleir (2009) proposed the use of multiple powerlaw segments. However, the use of these complex functions is often complicated by a limited number of direct measurements of water levels and discharge during floods, which are needed to parameterise the power-law segments related to high flow conditions. Thus, a single power-law curve is often considered a reasonable compromise and is used for many rivers (Di Baldassarre and Montanari, 2009). Additionally, in the river reach considered in this study, the direct measurements of discharge and water levels do not significantly deviate from a power-law curve (Franchini et al., 1999).

Operational river flow measurements and monitoring should be carried out to a high quality (ISO, 1996; ISO, 2010). During the actual water level measurements, components of uncertainty and changing channel properties result in errors and, consequently, the rating curve uncertainty has a significant effect on hydraulic model output (Hunter et al., 2007; Schmidt, 2002). Fuzzy-based approaches (e.g. Pappenberger et al., 2006; Westerberg et al., 2011) and analysis of errors (e.g. Di Baldassarre and Montanari, 2009; Domeneghetti et al., 2012) have been applied to characterise the uncertainty.

This study looks at the estimation of uncertainty in flood modelling, considering both inflow inaccuracy and model parameter uncertainty. The discharge uncertainty was derived through the rating curve by sampling from the distributions of the parameters of the power law. Parameter distributions were based on prior knowledge of possible ranges for the river gauging stations in the reach. An ensemble of input hydrographs was generated from the distributions of the parameters and was used to define the input inaccuracy in the hydraulic modelling.

\section{Study area and model set-up}

The study was carried out on a $98 \mathrm{~km}$ river reach (CremonaBorgoforte) of the River Po, Italy (Figure 1). It was anticipated that the use of a 1D model would be viable given the predominant 1D flow in a heavily embanked river, especially during high (and flood) flows. In total, 68 cross-sections were used; these were derived from a $2 \mathrm{~m}$ digital elevation model (DEM). The DEM was prepared in 2005 by augmenting floodplain data derived from laser scanners mounted on aircraft and, for the river bathymetry, multi-beam sonar was used. In addition, cross-sections from a field survey were acquired from the Interregional Authority of the River Po in 2005 (Di Baldassarre et al., 2009a).

The 1D hydraulic model HEC-RAS (Brunner, 2010a) was used to carry out the simulations. A time step of 1 min was used to fulfil the Courant condition and ensure stability of the model runs (Brunner, 2010a)

$$
\text { 1. } \Delta t \leqslant \frac{\Delta x}{u}
$$

where $\Delta t$ is the computation time step, $\Delta x$ is the cross-section spacing and $u$ is the flood wave velocity (Brunner, 2010b).

The model was set up with the upstream boundary condition hydrograph and a normal depth for the downstream boundary condition. This depth was calculated using Manning's formula 


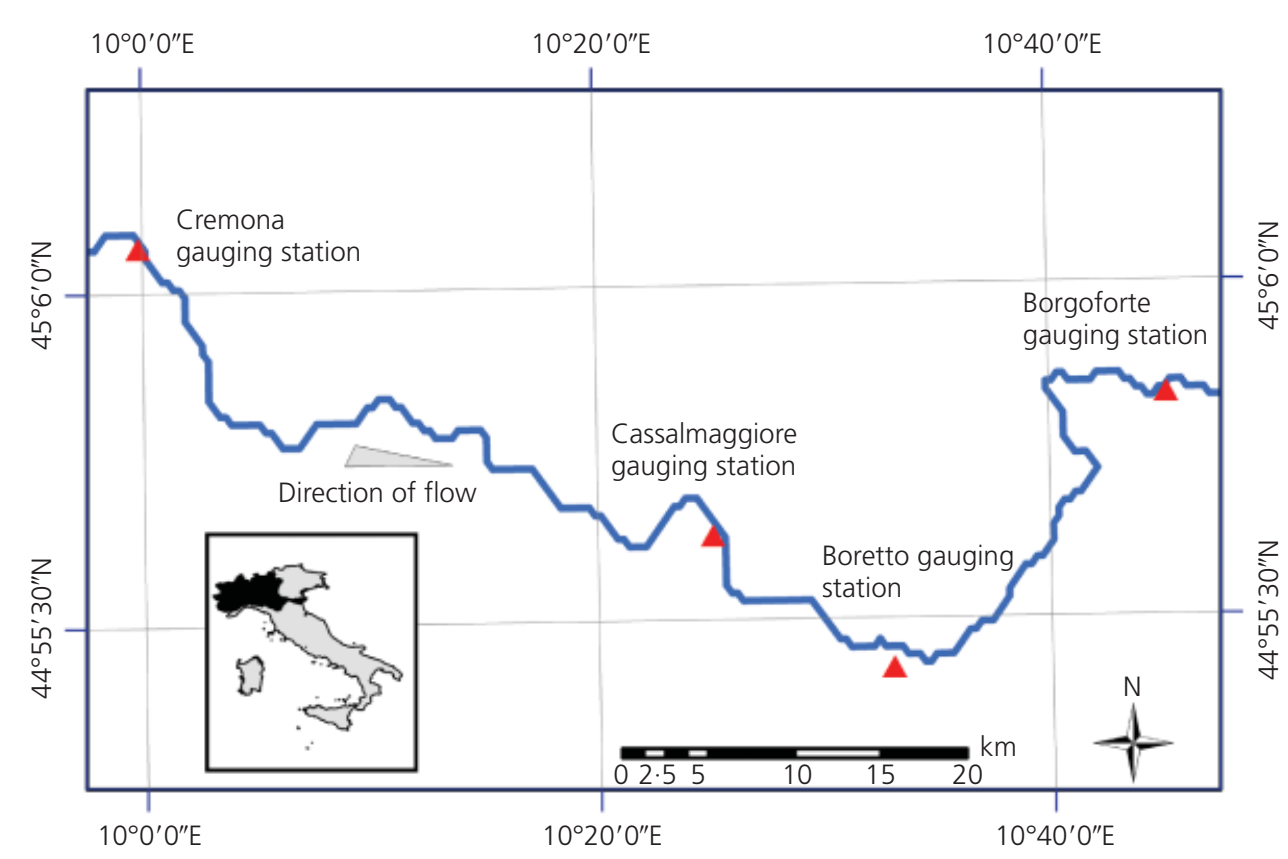

Figure 1. Study area, processed from data obtained from Lehner et al. (2006)

2. $Q=\frac{1}{n} A(h) R(h)^{2 / 3} S_{\mathrm{o}}^{1 / 2}$

(Brunner, 2010a) where $A$ is the area and $R$ is the hydraulic radius, which are a function of the water depth $(h), S_{0}$ is the userspecified friction slope, $Q$ is the discharge and $n$ is Manning's roughness coefficient.

The choice of the normal-depth downstream boundary condition, as opposed to using the observed water levels, was made to reduce backwater effects of using the observed water levels on the simulated water levels at the gauging stations. Water levels from two gauging stations (Cassalmaggiore and Boretto) were used in the evaluation of the model performance using the root mean square error (RMSE) (Hall, 2001)

3. $\mathrm{RMSE}=\left(\frac{1}{N} \sum_{t=1}^{N}[h(t)-\hat{h}(t \mid \theta)]^{2}\right)^{1 / 2}$

where $N$ is the number of simulations, $h(t)$ represents the observation at an instantaneous time $t$ and $\hat{h}$ is the simulated water level given the parameter set $\theta$ at the same time.

The uncertainty analysis was carried out using the generalised likelihood uncertainty estimation (Glue) approach, given its ease of understanding and implementation (Beven, 2006; Beven and Binley, 1992). The interested reader is referred to Beven (2006) and Stedinger et al. (2008) for further reading about alternative likelihood measures and approaches to implementing the Glue methodology. Behavioural model sets were selected where the RMSE values were found to be less than $1.0 \mathrm{~m}$. The choice of the rejection threshold for the RMSE is comparable to the policy of the Po River basin authority whereby a freeboard of $1 \mathrm{~m}$ is applied to the designed dyke levels (Brandimarte and $\mathrm{Di}$ Baldassarre, 2012)

4.

$$
w_{i}=\frac{\max \left(\mathrm{RMSE}_{i}\right)-\mathrm{RMSE}_{i}}{\max \left(\mathrm{RMSE}_{i}\right)-\min \left(\mathrm{RMSE}_{i}\right)}
$$

where $w_{i}$ is the weight assigned to objective function values for each behavioural simulation. The likelihood weights were then rescaled to a cumulative sum of 1 .

The Monte Carlo analysis toolbox was used for the uncertainty analysis (Wagener and Kollat, 2007). Identifiability plots were used to show the marginal distributions of the behavioural parameter sets (based on the likelihood). The plots consisted of a bar chart and a superimposed cumulative distribution (Wagener et al., 2002). A total of 10000 model simulations were run for each configuration of input parameters for the uncertainty analysis. This number was chosen based on two considerations - relative stabilisation of the mean and standard deviation of the output variable (water level).

\section{Input inaccuracy}

The inaccuracy of the upstream boundary condition was attributed to the rating curve uncertainty. For this study, a singlesegment power function was chosen for the conversion of water levels to generate the discharge hydrograph. Inflow inaccuracy 
was attributed to the function parameters $\alpha$ and $\beta$. The water level corresponding to zero discharge $H_{0}$ was taken from the cross-section geometry (Boiten, 2008)

5. $Q=\alpha\left(H-H_{0}\right)^{\beta}$

(Herschy, 1999). Figures 2 and 3 show the resulting ensembles of the rating curve and upstream boundary condition (Cremona gauging station, October 2000 flood event) achieved by varying the values of the rating curve parameters.

\section{Model conditioning}

Two prominent high-magnitude flood events were experienced in the river reach in November 1994 and October 2000 (Arpa, 1994, 2000). A statistical analysis of the historical discharge at Pontelagoscuro (a station downstream of the reach) approximated

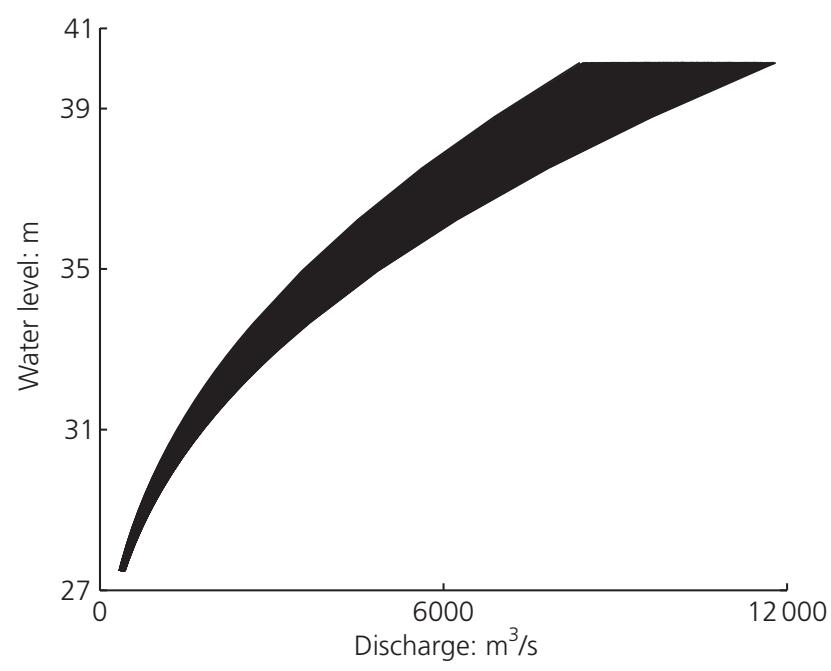

Figure 2. Rating curve uncertainty (Cremona station, October 2000)

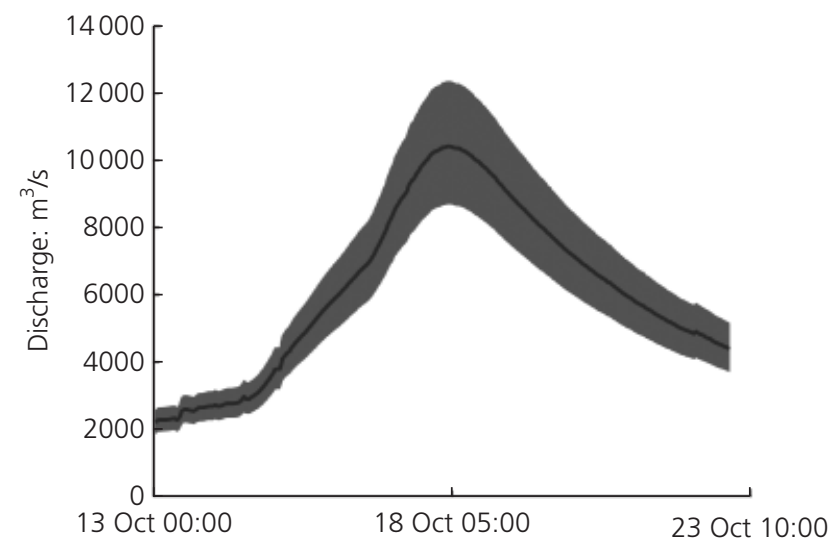

Figure 3. Resulting hydrograph ensemble for October 2000 flood event (at Cremona station) discharges of $12000 \mathrm{~m}^{3} / \mathrm{s}$ and $8000 \mathrm{~m}^{3} / \mathrm{s}$ as having return periods of 100 years and 10 years respectively (Marchi et al., 1995, 1996). Consequently, the November 1994 and the October 2000 flood events, with estimated peak discharges of 10800 and $11800 \mathrm{~m}^{3} / \mathrm{s}$ respectively were categorised as high-magnitude events (see Di Baldassarre et al., 2011).

The model was run in a Monte Carlo based framework to assess the parameter uncertainty using Glue. A prior uniform distribution for the rating curve parameters was used. The November 1994 event was taken as the dataset to condition the model and the October 2000 event was used for validation and uncertainty analysis. Parameter distributions were taken as $\alpha \sim U(4,12)$ and $\beta \sim U(2 \cdot 3,3 \cdot 0)$; these ranges were based on previous estimates of the parameters for the gauging stations along the reach (Arpa, 1994, 2000). The roughness coefficients that were used in this study were chosen from the documented ranges roughness parameters (Chow, 1959), with the main channel roughness ranging from 0.01 to $0.05 \mathrm{~m}^{1 / 3} / \mathrm{s}$ and floodplain roughness values ranging from 0.04 to $0 \cdot 11 \mathrm{~m}^{1 / 3} / \mathrm{s}$.

From Figure 4, the power-function parameter $\beta$ and the main channel roughness coefficient show central tendencies in the posterior distribution.

\section{Model validation}

The roughness and rating parameter (effective) values, for use in the validation of the model using the October 2000 flood event, were sampled from the empirical distributions of the parameters derived from the model conditioning (Figure 4).

The model ensemble was able to simulate the peak of the flood event within a $90 \%$ confidence interval (CI). However, the model was not able to simulate the kink in the observed data (see Figure 5). This was attributed to the floodwater flowing out of bank, similar to the findings reported by Di Baldassarre and Montanari (2009). Given the availability of the high water marks of the October 2000 flood event, the model was also tested in simulating this observation.

Figure 6 shows that the model ensemble performed well in the simulation of the high water marks within a confidence interval of $90 \%$. Thus, the parameter uncertainty analysis was based on the available water levels at the internal gauging stations.

\section{Uncertainty analysis}

The uncertainty analysis was based on the October 2000 flood event and the water levels at the two internal gauging stations. The analysis was carried out in three cases corresponding to the following uncertainty sources

- input inaccuracy (case 1) Figure 7

roughness coefficient uncertainty (case 2) Figure 8

- combined inflow inaccuracy and roughness uncertainty (case 3) Figure 9 . 
Flood modelling: parameterisation and inflow uncertainty

Mukolwe, Di Baldassarre, Werner and

Solomatine

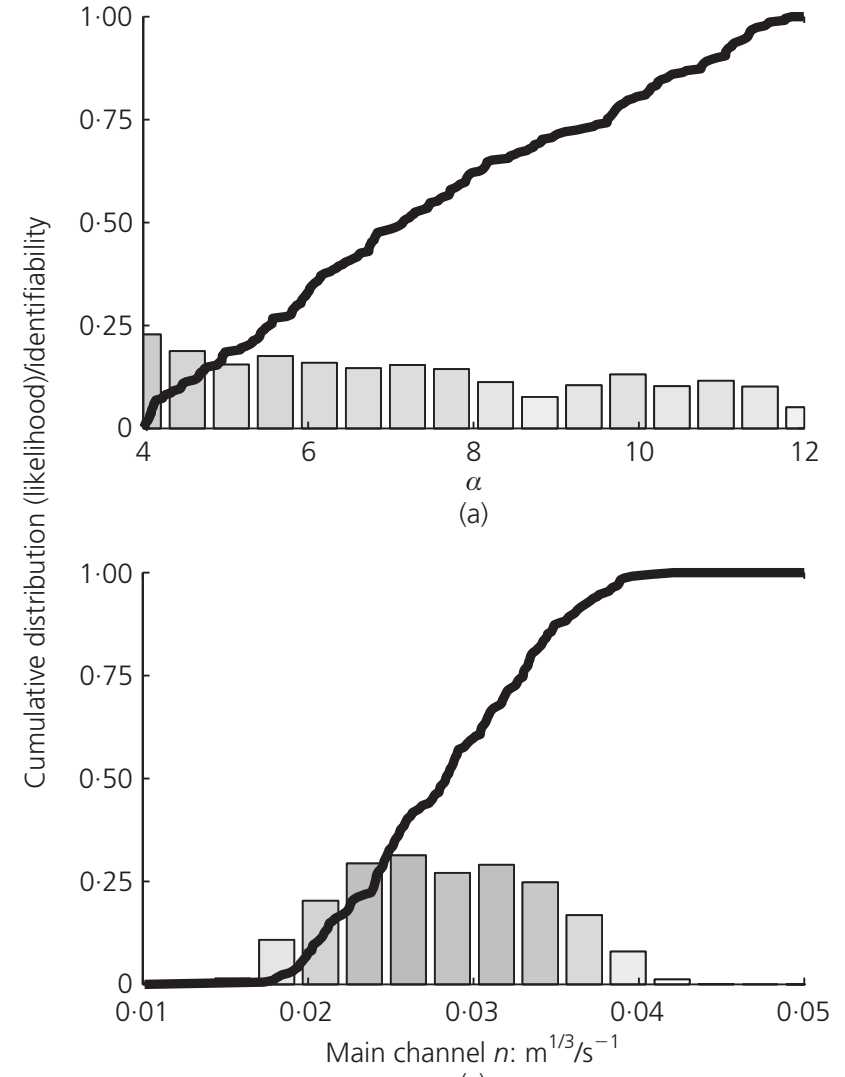

(c)

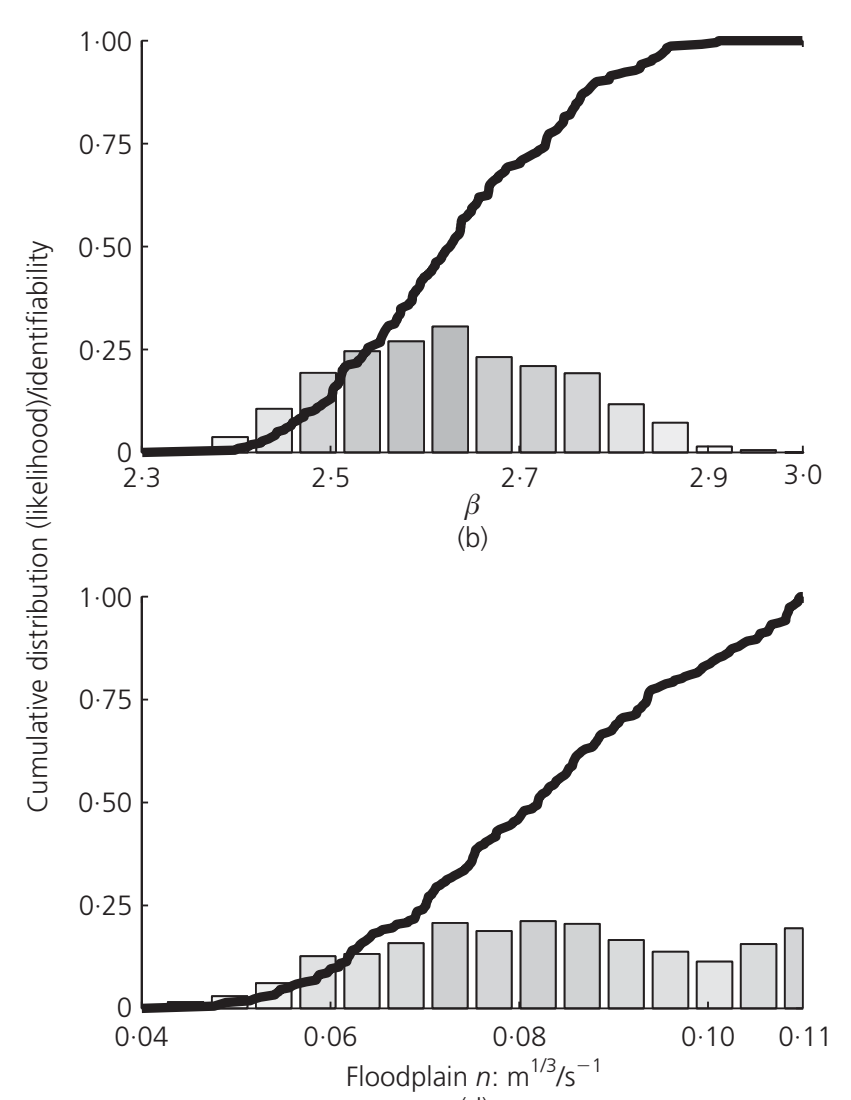

(d)

Figure 4. Identifiability plots for the November 1994 flood event

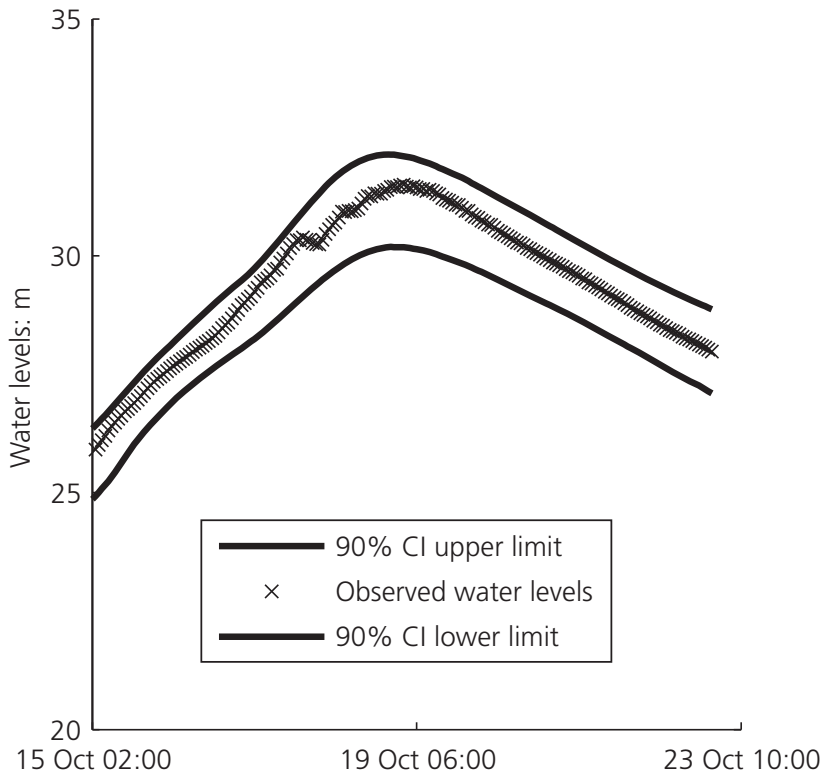

(a)

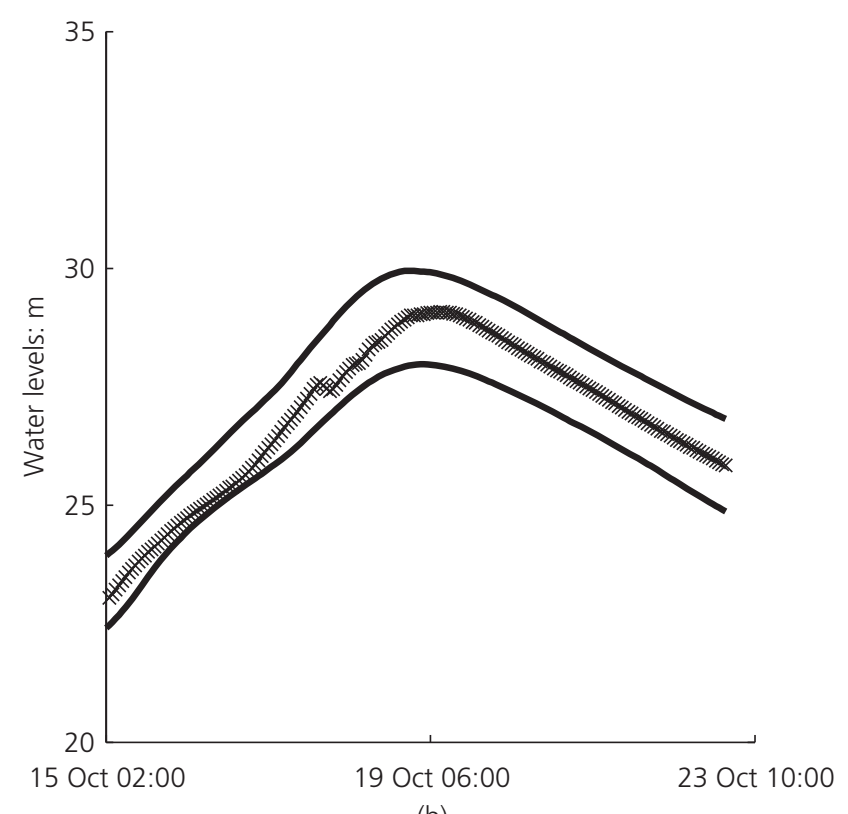

(b)

Figure 5. Model validation: observed water level in October 2000 at the internal gauging stations: (a) Cassalmaggiore; (b) Boretto 
Flood modelling: parameterisation and inflow uncertainty

Mukolwe, Di Baldassarre, Werner and

Solomatine

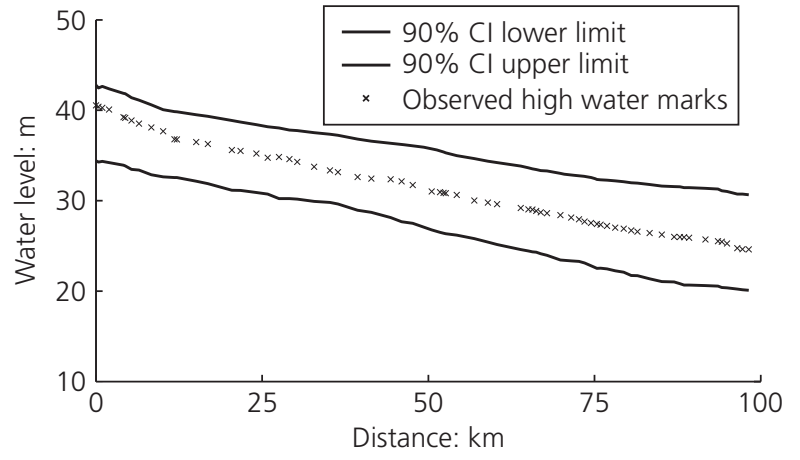

Figure 6. Model validation: high water marks October 2000 flood event

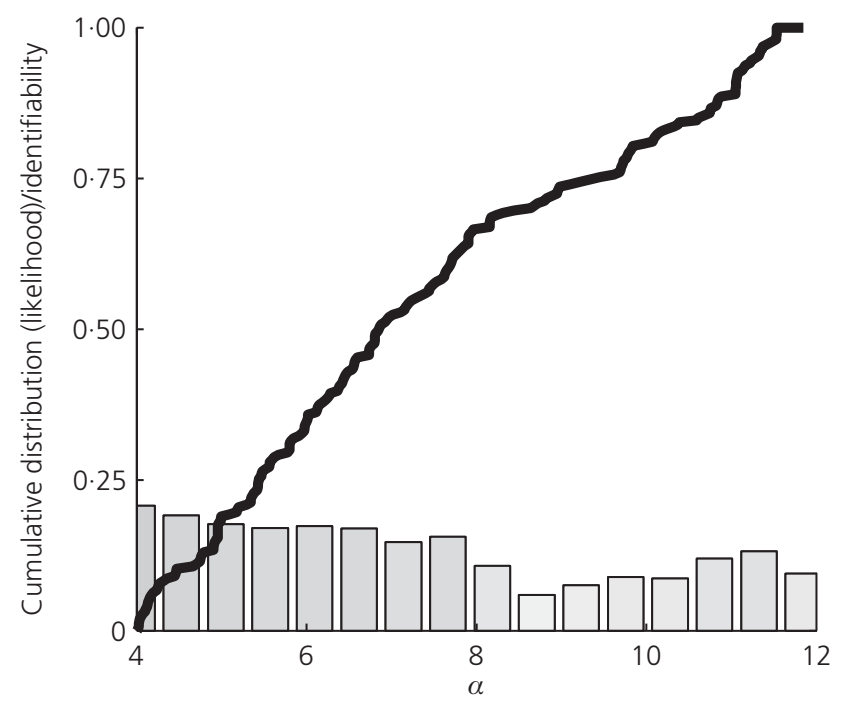

(a)

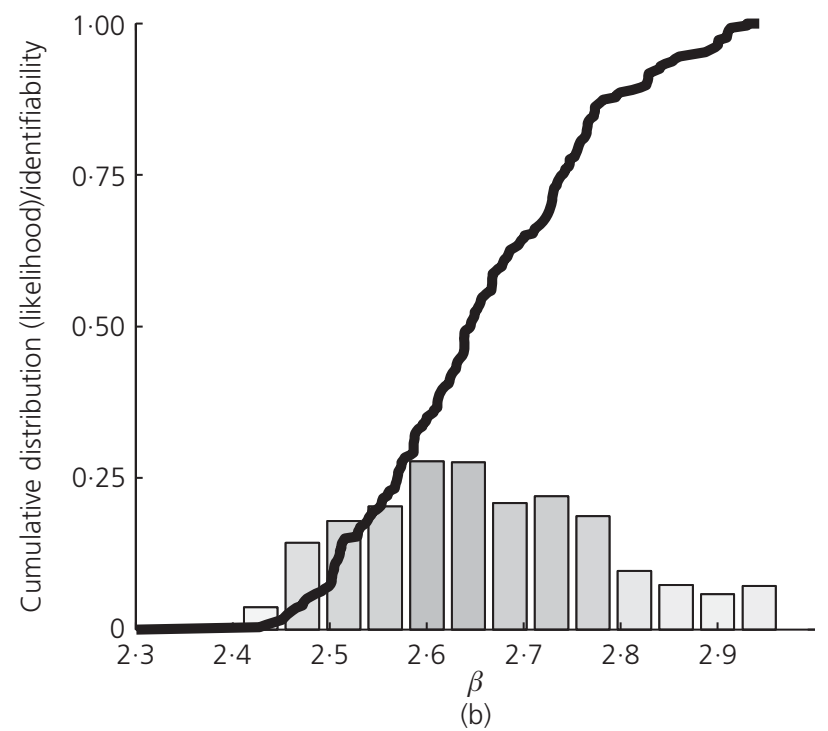

Figure 7. Identifiability plots: case 1, rating curve parameters

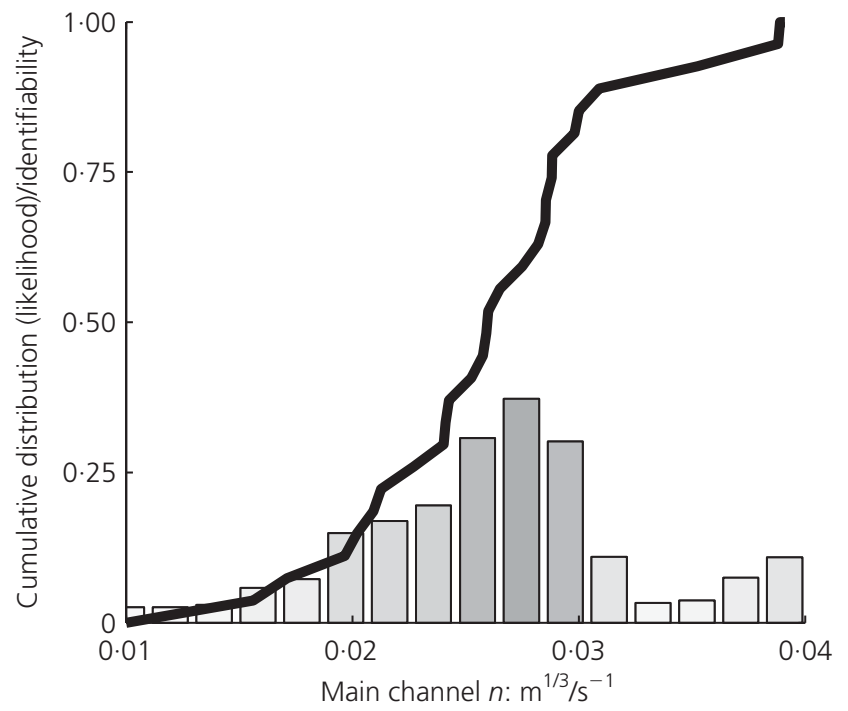

(a)

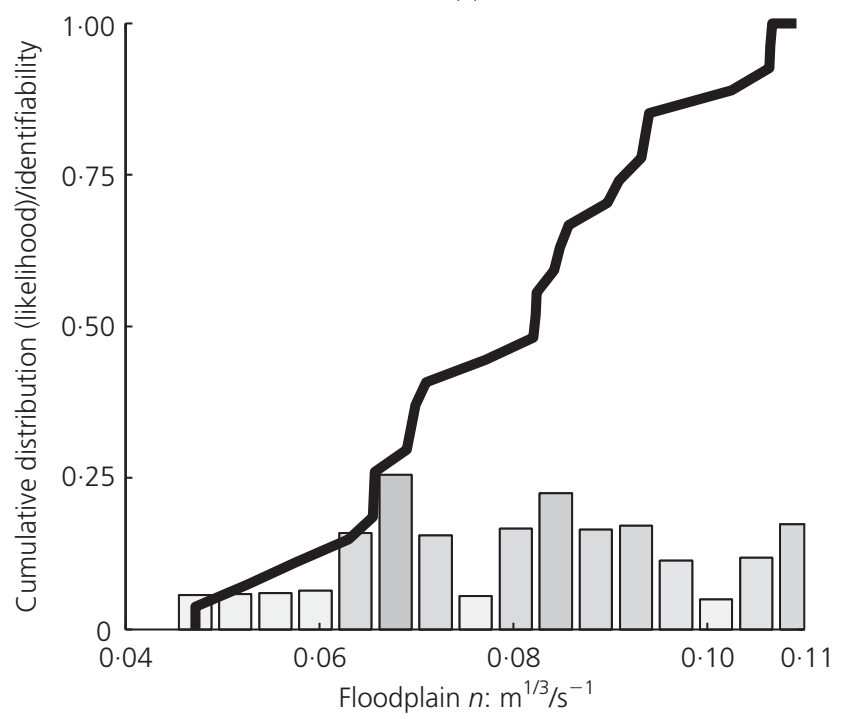

(b)

Figure 8. Identifiability plots: case 2 , roughness parameters

Figure 8 shows the results of the case 2 ensemble. The ensemble resulted in a large number of non-behavioural models and an exception was made to use a threshold of $1.5 \mathrm{~m}$ for the RMSE to show results for the case.

\section{Discussion}

The results of the uncertainty analysis showed that the main channel roughness was more sensitive than the floodplain roughness, which is similar to results reported in other studies (e.g. Pappenberger et al., 2006; Werner et al., 2005).The sensitivity of the main channel roughness (see Figures 4, 8 and 9) is attributed to the high conveyance capacity of the main channel section, most especially for the predominant 1D flow (e.g. Werner et al., 2005). However, for the combined analysis (case 3) the powerfunction parameter $\beta$ (therefore the inflow uncertainty) is the most sensitive. This is evident from the distinct identifiability plot 


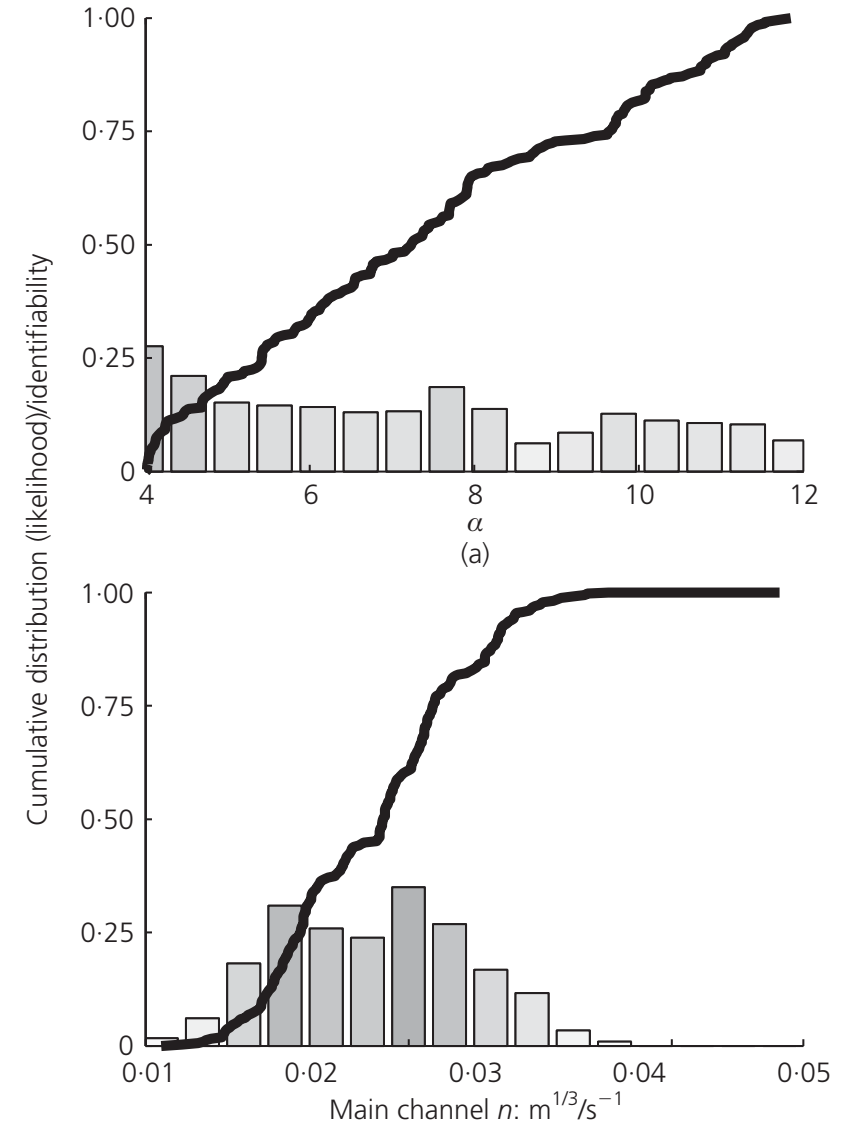

(c)

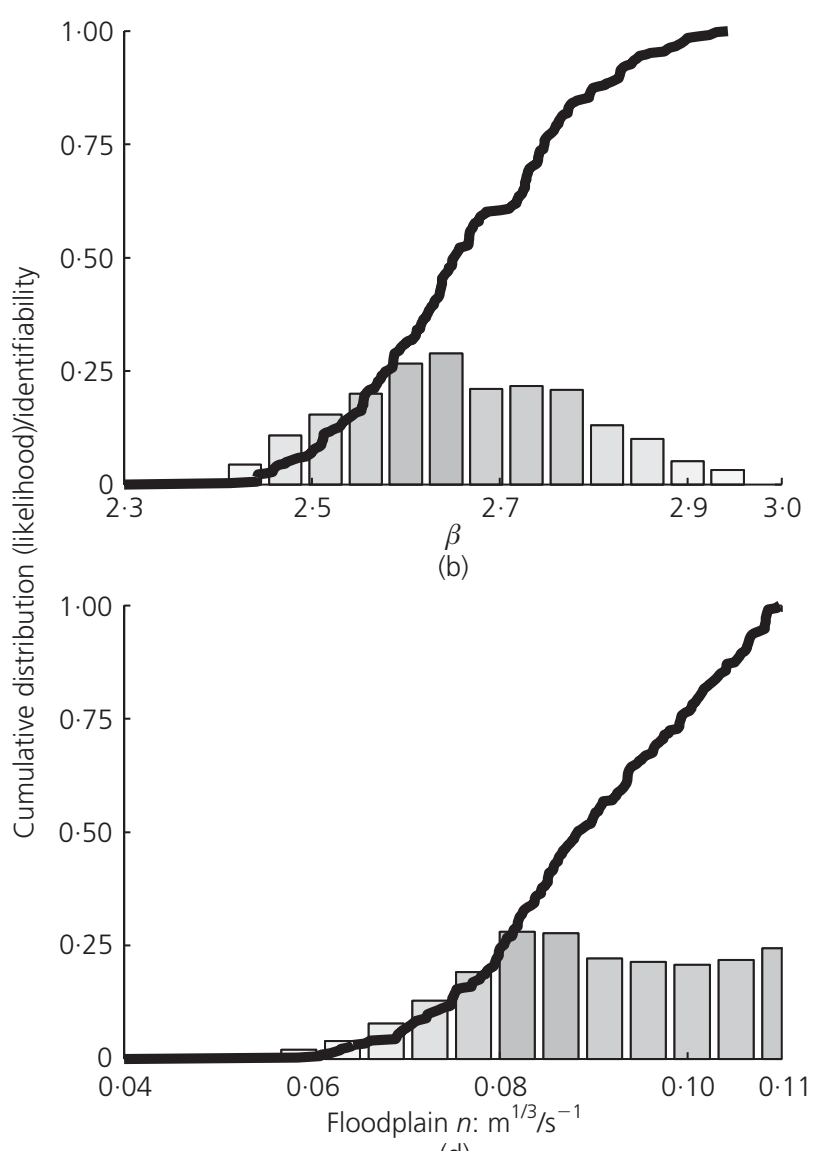

(d)

Figure 9. Identifiability plots: case 3, combined parameters

of parameter $\beta$ (Figures 4, 7 and 9), especially Figure 4, whereby the posterior distribution shows a strong central tendency in contrast to the prior uniform distribution. Additionally, the results of cases 1 and 3 (Figures 7 and 9) show that the power-function parameters are more dominant in achieving a higher likelihood value when compared with case 2 (Figure 8), whereby the roughness parameters were unable to adequately produce behavioural models.

Figures 8 and 9 (cases 2 and 3 ) show that the optimal main channel roughness values were $0.0365 \mathrm{~m}^{1 / 3} / \mathrm{s}$ and $0.02 \mathrm{~m}^{1 / 3} / \mathrm{s}$ respectively; this implies that the power-function and the roughness parameters compensate for each other (e.g. Romanowicz and Beven, 2003). Consequently, the discussion and deductions were carried out with reference to a set of parameters rather than single values.

In the case of the power-function parameters, parameter $\beta$ is more sensitive than $\alpha$; in Figures 4,7 and $9, \beta$ shows a distinct distribution with a central tendency. Given that the parameter is an exponent (Equation 5), the contribution to the magnitude of the discharge is high.

The results of this study show that the 1D HEC-RAS model effectively simulates the peak discharge within the $90 \%$ CI of the model simulation ensembles, which is evident in Figure 5. However, in the same figure, the observation data show a kink in the observed data, which was not simulated by the model. Considering the fact that the River Po is heavily embanked, with primary and secondary dykes (Marchi et al., 1995, 1996), this inability of the model to adequately simulate this observed kink shows that the lateral (2D) flow effects of out-of-bank flow could not be effectively simulated. In addition, the HEC-RAS model uses the vertically divided channel method (VDCM) to calculate the discharge conveyance. The VDCM does not account for the turbulent momentum exchanges between the main channel flow and the floodplain flow, thus resulting in errors in the simulated discharge (Lambert and Sellin, 1996; Myers et al., 2001; Werner and Lambert, 2007); the discrepancy thus may be attributed to the model structure error. In the 1D model, the only parameters that can be adjusted are the roughness coefficients to compensate for this additional energy loss, which may be inadequate, especially for river channels with varying local conditions (see Figure 8 ). The use of higher order models or hybrid models (1D2D) could overcome the inability of the $1 \mathrm{D}$ model to simulate lateral flows (e.g. Prestininzi et al., 2011). Essentially, such a decision would be taken by considering the nature of the channel 
geometry and local conditions, and available computation capacity.

Figure 9 shows that, for the best performing models, the value of the floodplain roughness was high. This is attributed to the fact that, during the October 2000 event, the channel experienced a peak flow (estimated as a 1:100 year flood). As the water depth increases, the main channel and the floodplain sections of the river behave as one channel with predominant 1D flow (Figure 10), and the shear stress between the flow in the main channel and the floodplain decreases; this means that the sensitivity of the floodplain roughness increases.

A comparison of the parameters in Figures 4, 7 and 8 shows that the power-function parameters are more significant in matching the discharge of the October 2000 flood event (Figure 7) as compared with the roughness parameters (Figure 8). Thus, inclusion of the power-function parameters as well as the roughness parameters (Figure 9) shows the ability of the model ensemble to achieve a better fit of the observed and simulated water levels. Moreover, given the disparity of local and global performance measures (see Pappenberger et al., 2007), the inclusion of variable power-function parameters gives the model greater flexibility to simulate the water levels and high water marks (along the length of the reach) when conditioned on water level data (see Figures 5 and 6). The choice of the rejection threshold, while conditioning the model, and the resulting model ensemble validation in Figures 5 and 6 indicate that the rejection criteria may have been lowered to get a narrower CI band. The subjective choice of the rejection criteria may thus be guided by the accuracy of the simulated water levels.

\section{Conclusions}

A methodology for the inclusion of input uncertainty (resulting from rating curve inaccuracy) and roughness conditions propagated through a 1D hydraulic model has been presented. Four coefficients were parameterised (two for the rating curve and two for the roughness specification in the model) and analysed within the Glue framework. Model performance was based on the two internal gauging stations using the RMSE as the objective function, whereby the rejection criterion for non-behavioural models was an RMSE value of $1 \mathrm{~m}$.

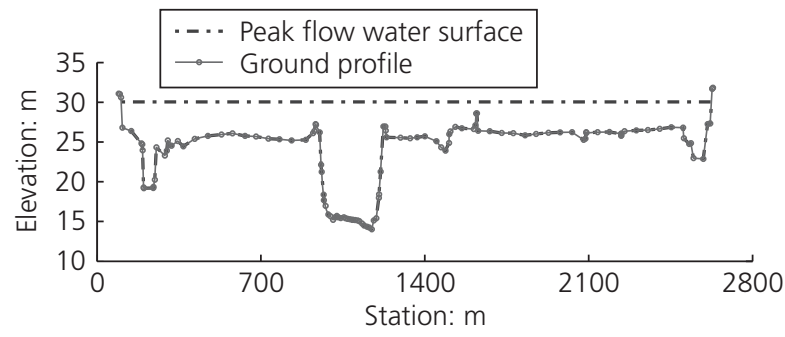

Figure 10. Example cross-section at the chainage $39239.45 \mathrm{~m}$ showing the dyke system during peak flow
The model was conditioned and validated using two independent flood events. The resulting model was able to simulate observed water levels and the high water marks of the October 2000 flood event, when conditioned on the observed November 1994 flood event water levels, due to significance of inflow inaccuracy.

The inclusion of the uncertainty of the rating curve parameters allows for an ensemble of input hydrographs to be sampled to represent uncertainties resulting from local effects at the gauging station; more specifically, for 1D hydraulic models where the model structure is predominantly governed by 1D flow with all energy losses due to friction and turbulence lumped on to the roughness parameters. Increasing the parameterisation by including the rating curve parameters gives the model more flexibility to represent uncertainties in the channel roughness and inputs. However, when inflow inaccuracy is considered, there is a possibility for the inadequacy of the model structure to be compensated by the roughness values.

Analysis of the parameters showed a complex relationship whereby the parameters compensate each other. Evaluation and subsequent deductions using the model should then be done by analysing the parameters as a combined set. The increase in parameterisation increased the ability of the model to simulate the input inaccuracy and the effective roughness. It is proposed that the increased hydraulic model parameterisation (to account for input uncertainty) and information on parameter behaviour may be included in probabilistic outputs to end users. Thus, the probabilistic output would give users information on the level of certitude of the model output when compared with the different sources of uncertainty.

\section{Acknowledgements}

This paper is the result of MSc thesis work done by Micah M. Mukolwe at Unesco-IHE Institute for Water Education, parts of which was presented at the European Geosciences Union 2011 Leonardo Conference in Bratislava, Slovakia, on 23-25 November 2011. The authors are grateful to the Netherlands Fellowship Programme and the European Commission for funding this study, which is part of the FP7 KultuRisk project (no. 265280).

\section{REFERENCES}

Arpa (Regional Agency for Prevention and Environment) (1994) Hydrological Records: Area Hydrology - Part 2.

Meteorological and Hydrological service. Emilia-Romagna, Italy (in Italian).

Arpa (2000) Hydrological Records: Area Hydrology - Part 2. Meteorological and Hydrological Service. Emilia-Romagna, Italy (in Italian).

Bates PD (2012) Integrating remote sensing data with flood inundation models: how far have we got? Hydrological Processes 26(16): 2515-2521.

Bates PD, Horritt MS and Fewtrell TJ (2010) A simple inertial formulation of the shallow water equations for efficient two- 
dimensional flood inundation modelling. Journal of Hydrology 387(1-2): 33-45.

Beven K (2006) A manifesto for the equifinality thesis. Journal of Hydrology 302(1-2): 18-36.

Beven K and Binley A (1992) The future of distributed models: model calibration and uncertainty prediction. Hydrological Processes 6(3): 279-298.

Boiten W (2008) Hydrometry: A Comprehensive Introduction to the Measurement of Flow in Open Channels. CRC Press/ Balkema, Rotterdam, the Netherlands.

Braca G (2008) Stage-discharge Relationships in Open Channels: Practices and Problems. Universita degli Studi di Trento, Dipartimento di Ingegneria Civile e Ambientale, Trento, Italy, Foralps technical report 11.

Brandimarte L and Di Baldassarre G (2012) Uncertainty in design flood profiles derived by hydraulic modelling. Hydrology Research 43(6): 753-761.

Brunner G (2010a) HEC-RAS, River Analysis System - Hydraulic Reference Manual. Hydrologic Engineering Center, US Army Corps of Engineers, Davis, CA, USA.

Brunner GW (2010b) HEC-RAS River Analysis System: User'S Manual. US Army Corps of Engineers, Institute for Water Resources, Hydrologic Engineering Center, Davis, CA, USA.

Chow VT (1959) Open-channel Hydraulics, International student edn. McGraw-Hill, Kogakusha, Tokyo, Japan.

Clarke RT (1999) Uncertainty in the estimation of mean annual flood due to rating-curve indefinition. Journal of Hydrology 222(1-4): 185-190.

Di Baldassarre G and Montanari A (2009) Uncertainty in river discharge observations: a quantitative analysis. Hydrology and Earth System Sciences 13(6): 913-921.

Di Baldassarre G, Schumann G and Bates PD (2009b) A technique for the calibration of hydraulic models using uncertain satellite observations of flood extent. Journal of Hydrology 367(3-4): 276-282.

Di Baldassarre G, Schumann G and Bates P (2009a) Near real time satellite imagery to support and verify timely flood modelling. Hydrological Processes 23(5): 799-803.

Di Baldassarre G, Laio F and Montanari A (2011) Effect of observation errors on the uncertainty of design floods. Physics and Chemistry of the Earth, Parts $A / B / C$ 42-44: 85-90.

Domeneghetti A, Vorogushyn S, Castellarin A, Merz B and Brath A (2012) Effects of rating-curve uncertainty on probabilistic flood mapping. Hydrology and Earth System Sciences Discussions 9(8): 9809-9845.

Dottori F and Todini E (2011) Developments of a flood inundation model based on the cellular automata approach: testing different methods to improve model performance. Physics and Chemistry of the Earth, Parts $A / B / C$ 36(7-8): 266-280.

Fenton JD (2001) Rating curves: Part 1 - correction for surface slope. Proceedings of 6th Conference on Hydraulics in Civil Engineering: The State of Hydraulics, Australia. pp. 309-317. Franchini M, Lamberti P and Di Giammarco P (1999) Rating curve estimation using local stages, upstream discharge data and a simplified hydraulic model. Hydrology and Earth System Sciences 3(4): 541-548.

Hall M (2001) How well does your model fit the data? Journal of Hydroinformatics 3(1): 49-55.

Herschy RW (1999) Hydrometry: Principles and Practices. Wiley, Chichester, UK.

Hunter NM, Bates PD, Horritt MS, De Roo PJ and Werner MGF (2005a) Utility of different data types for calibrating flood inundation models within a Glue framework. Hydrology and Earth System Sciences 9(4): 412-430.

Hunter NM, Horritt MS, Bates PD, Wilson MD and Werner MGF (2005b) An adaptive time step solution for raster-based storage cell modelling of floodplain inundation. Advances in Water Resources 28(9): 975-991.

Hunter NM, Bates PD, Horritt MS and Wilson MD (2007) Simple spatially-distributed models for predicting flood inundation: a review. Geomorphology 90(3-4): 208-225.

ISO (1996) ISO 1100-1: 1996 Measurement of liquid flow in open channels - Part 1: Establishment and operation of a gauging station. ISO, Geneva, Switzerland.

ISO (2010) ISO 1100-2: 2010 Hydrometry - Measurement of liquid flow in open channels - Part 2: determination of the stage-discharge relationship. ISO, Geneva, Switzerland.

Kidson R and Richards K (2005) Flood frequency analysis: assumptions and alternatives. Progress in Physical Geography 29(3): 392-410.

Lambert MF and Sellin R (1996) Discharge prediction in straight compound channels using the mixing length concept. Journal of Hydraulic Research 34(3): 381-394.

Lehner B, Verdin K and Jarvis A (2006) HydroSHEDS Technical Documentation. World Wildlife Fund US, Washington, DC, USA. See http://hydrosheds.cr.usgs.gov (accessed 21/02/2012).

Loucks DP, Beek EV, Stedinger JR, Dijkman JPM and Villars MT (2005) Water Resources Systems Planning and Management: An Introduction to Methods, Models and Applications. Unesco, Paris, France.

Marchi E, Roth G and Siccardi F (1995) The November 1994 flood event on the Po River: structural and non-structural measures against inundations. Proceedings of US-Italy Research Workshop on the Hydrometeorology, Impact, and Management of Extreme Floods, Perugia, Italy.

Marchi E, Roth G and Siccardi F (1996) The Po: centuries of river training. Physics and Chemistry of The Earth 20(5-6): 475478.

McCarthy S, Tunstall S, Parker D, Faulkner H and Howe J (2007) Risk communication in emergency response to a simulated extreme flood. Environmental Hazards 7(3): 179-192.

Montanari A (2007) What do we mean by 'uncertainty'? The need for a consistent wording about uncertainty assessment in hydrology. Hydrological Processes 21(6): 841-845.

Myers W, Lyness J and Cassells J (2001) Influence of boundary roughness on velocity and discharge in compound river channels. Journal of Hydraulic Research 39(3): 311-319.

Neal JC, Bates PD, Fewtrell TJ et al. (2009) Distributed whole city 
water level measurements from the Carlisle 2005 urban flood event and comparison with hydraulic model simulations. Journal of Hydrology 368(1-4): 42-55.

Neal JC, Schumann G and Bates P (2012) A sub-grid channel model for simulating river hydraulics and floodplain inundation over large and data sparse areas. Water Resources Research 48(11): 1-16, W11506.

Pappenberger F and Beven K (2006) Ignorance is bliss: or seven reasons not to use uncertainty analysis. Water Resources Research 42: 1-8, W05302.

Pappenberger F, Beven K, Horritt M and Blazkova S (2005) Uncertainty in the calibration of effective roughness parameters in HEC-RAS using inundation and downstream level observations. Journal of Hydrology 302(1-4): 46-69.

Pappenberger F, Matgen P, Beven KJ et al. (2006) Influence of uncertain boundary conditions and model structure on flood inundation predictions. Advances in Water Resources 29(10): $1430-1449$.

Pappenberger F, Beven K, Frodsham K, Romanowicz R and Matgen P (2007) Grasping the unavoidable subjectivity in calibration of flood inundation models: a vulnerability weighted approach. Journal of Hydrology 333(2-4): 275-287.

Petersen-Øverleir A (2005) A Hydraulics Perspective on the Power-law Stage-discharge Rating Curve. Norwegian Water Resources and Energy Directorate, Oslo, Norway, NVE report 05-05.

Prestininzi P, Di Baldassarre G, Schumann G and Bates PD (2011) Selecting the appropriate hydraulic model structure using low-resolution satellite imagery. Advances in Water Resources 34(1): 38-46.

Quiroga VM, Popescu I, Solomatine DP and Bociort L (2013) Cloud and cluster computing in uncertainty analysis of integrated flood models. Journal of Hydroinformatics 15(1): $55-70$.

Reitan T and Petersen-Øverleir A (2009) Bayesian methods for estimating multi-segment discharge rating curves. Stochastic
Environmental Research and Risk Assessment 23(5): 627642.

Romanowicz R and Beven K (2003) Estimation of flood inundation probabilities as conditioned on event inundation maps. Water Resources Research 39(3): 1073.

Schmidt AR (2002) Analysis of Stage-discharge Relations for Open-channel Flows and Their Associated Uncertainties. $\mathrm{PhD}$ thesis, University of Illinois at Urbana, Champaign, IL, USA.

Schumann G, Bates P, Horritt M, Matgen P and Pappenberger F (2009) Progress in integration of remote sensing-derived flood extent and stage data and hydraulic models. Reviews of Geophysics 47(4): 1-20, RG4001.

Stedinger JR, Vogel RM, Lee SU and Batchelder R (2008) Appraisal of the generalized likelihood uncertainty estimation (GLUE) method. Water Resources Research 44(12): 1-17, W00B06.

Wagener T and Kollat J (2007) Numerical and visual evaluation of hydrological and environmental models using the Monte Carlo analysis toolbox. Environmental Modelling and Software 22(7): 1021-1033.

Wagener T, Lees M and Wheater H (2002) A toolkit for the development and application of parsimonious hydrological models. In Singh VP and Frevert DK Mathematical Models of Large Watershed Hydrology. Water Resources Publications, pp. 91-140.

Werner M and Lambert MF (2007) Comparison of modelling approaches used in practical flood extent modelling. Journal of Hydraulic Research 45(2): 202-215.

Werner M, Hunter N and Bates P (2005) Identifiability of distributed roughness data in flood extent estimation. Journal of Hydrology 314(1-4): 139-157.

Westerberg I, Guerrero JL, Seibert J, Beven KJ and Halldin S (2011) Stage-discharge uncertainty derived with a nonstationary rating curve in the Choluteca River, Honduras. Hydrological Processes 25(4): 603-613.

\footnotetext{
WHAT DO YOU THINK?

To discuss this paper, please email up to 500 words to the editor at journals@ice.org.uk. Your contribution will be forwarded to the author(s) for a reply and, if considered appropriate by the editorial panel, will be published as a discussion in a future issue of the journal.

Proceedings journals rely entirely on contributions sent in by civil engineering professionals, academics and students. Papers should be 2000-5000 words long (briefing papers should be 1000-2000 words long), with adequate illustrations and references. You can submit your paper online via www.icevirtuallibrary.com/content/journals, where you will also find detailed author guidelines.
} 